\title{
Caught in the subglottic web-unanticipated difficult intubation.
}

\author{
Sindhu Sabapathy ${ }^{1 *}$, Prasad Kulkarni ${ }^{1}$, Nithya Hanumanthappa ${ }^{1}$, Sarangi TK ${ }^{2}$ \\ ${ }^{1}$ Department of Anesthesiology, MVJ Medical College and Research Hospital, Bangalore, Karnataka, India \\ ${ }^{2}$ School of Biosciences and Technology, VIT University, Vellore, Tamil Nadu, India
}

\begin{abstract}
Unanticipated difficult airway still forms about $93 \%$ of the total number of difficult airway scenarios encountered. Difficult airway can be due to difficulty in mask ventilation, difficult laryngoscopy or difficulty in intubation. Difficult intubation can be due to a number of causes. Pathologies like enlarged lingual tonsil, valecular or epiglottic cysts, laryngeal papillomas, hyperplastic mucosal folds, oropharyngeal stenosis lead to difficulty visualizing the larynx. Tracheal stenosis, laryngeal webs, tumors of the larynx, airway trauma and undetected mediastinal masses lead to difficulty in advancing the endotracheal tube. Management of these cases is always challenging. Although a thorough history that includes previous endotracheal intubation, weight changes, episodes of dyspnea or wheeze may help identify at risk patients, very often these patients may be asymptomatic and the pathology may not be until the time of laryngoscopy and intubation. At the time of unanticipated crisis, following the stepwise protocol of difficult airway and being prepared for surgical airway access can prevent complications and save the life of the patient. Here we present two such cases of unanticipated difficult airway how we managed them. Post-operatively these patients were found to have laryngeal webs.
\end{abstract}

Keywords: Cholecystectomy, Laryngeal webs, Subglottic web.

Accepted on July 5, 2018

\section{Caught in the Subglottic Web}

Obstruction to advancement of endotracheal tube is an important cause of unanticipated difficult airway. We present two such case reports where the cause of obstruction was shown to be laryngeal webs on CT scan in the post-operative period.

\section{Case Report 1}

A 48-y-old female with chronic calculus cholecystitis was posted for an elective open cholecystectomy. Pre-operative evaluation included a detailed history of co-morbid conditions which included dyspnea or asthma, history of previous surgeries including any history of problems encountered during anesthesia. Significant positive history included symptoms of acid peptic disease. The general and systemic examination was normal. A preoperative airway examination revealed the following, malampatti grade I, adequate inter- incisor gap of 3 fingers, thyro-mental distance of $9 \mathrm{~cm}$, neck circumference 32 $\mathrm{cm}$, height $158 \mathrm{~cm}$ and no features suggestive of difficult airway. Following pre-oxygenation and induction, adequate mask ventilation was confirmed. Vecuronium $0.1 \mathrm{mg} / \mathrm{kg}$ i.v. was given and was followed by direct laryngoscopy which revealed Cormack Lehane view I. First attempt to pass the tube 7.5 size cuffed endotracheal tube was unsuccessful as the tube could not be passed beyond the glottis, and the tube was trapped just after the cuff of the ET tube was in. The tube would neither be inserted further nor removed, since we were able to ventilate with this tube we gradually removed the tube with twisting movements. A second attempt with a 6.0 size cuffed endotracheal tube resulted in successful endotracheal intubation. There was no difficulty in extubating the patient after the procedure. Post operatively the patient was subjected to CT Neck, which revealed a subglottic web (Figure 1).

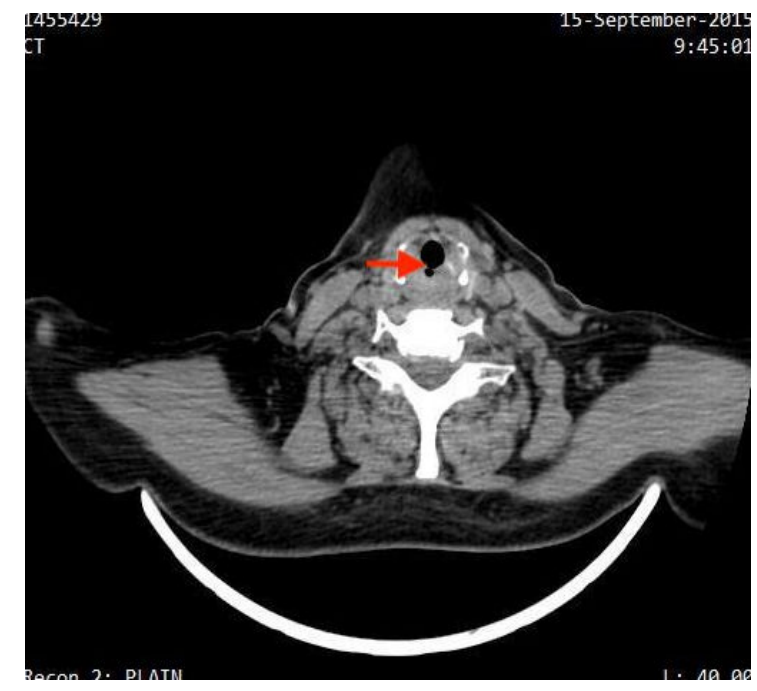

Figure 1. CT Neck belonging to patient from Case Report 1: Red arrow Showing a laryngeal web. 


\section{Case Report 2}

A 56-y-old male with an intestinal obstruction was posted for an emergency laparotomy. Although the patient was in significant distress due to pain abdomen, there was no history of pre-existing co-morbid conditions, previous surgeries or mechanical ventilation. A pre-operative airway examination revealed adequate inter-incisor gap of 3 fingers, Malampatti grade III, a short neck and body-mass index of $37.5 \mathrm{~kg} / \mathrm{m}^{2}$. Difficult airway was anticipated and the difficult airway cart was kept ready. Also a rapid sequence induction was planned in view of the intestinal obstruction. After pre-oxygenation and induction adequate mask ventilation was confirmed though it was difficult and performed with two hands technique. After instituting cricoid pressure, succinyl choline was given and was followed by direct laryngoscopy, which revealed a Cormack Lehane grade III and the attempt to intubation failed due to obstruction to intubation (Figure 2).

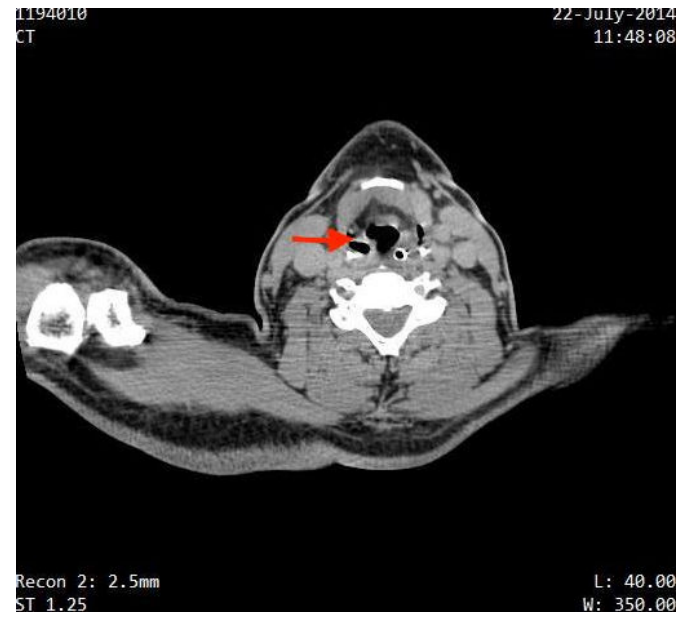

Figure 2. CT Neck belonging to patient from Case Report 2: Red arrow Showing a laryngeal web.

Decision was taken to do a bougie-guided intubation, a bougie was passed but the tube could not be rail roaded beyond the glottis. Attempts to remove the bougie revealed that the bougie was stuck in the glottis. There was an episode of desaturation when the oxygen saturation dropped to $60 \%$ during this period. A second dose of succinyl choline was given in an attempt to relieve any laryngospasm and the bougie was finally removed with difficulty. The patient was mask ventilated and awakened. Retrospectively a CT scan of neck revealed a subglottic web.

\section{Discussion}

Difficult intubation can be due to a number of causes. Pathologies like enlarged lingual tonsil [1], valecular or epiglottic cysts [2], laryngeal papillomas, hyperplastic mucosal folds, oropharyngeal stenosis [3] lead to difficulty visualizing the larynx. Tracheal stenosis [4], congenital [5] or acquired laryngeal webs [6], tumors of the larynx [7], airway trauma, subglottic stenosis and undetected mediastinal masses lead to difficulty in advancing the endotracheal tube. Conditions like the pharyngeal pouch [8] leads to difficulty in identifying the laryngeal aperture whereas the tracheal bronchus may lead to hypoxia after intubation.

The incidence of a congenital laryngeal web is 1 in 10000 [9]. Laryngeal webs represent a failure of recanalization of the glottic airway in the early weeks of embryogenesis [10]. Congenital webs may be a part of syndromes like DiGeorge syndrome, Velocardiofacial syndrome or CATCH 22 syndrome [11]. They are mostly located anteriorly [10]. Acquired lesions are more common. Acquired causes include post traumatic webs [11], post-inflammatory i.e. following tuberculosis or diphtheria and iatrogenic which include intra-laryngeal surgery or traumatic intubation. Most patients with a subglottic web are asymptomatic. They may present with symptoms of chronic obstructive lung disease [12] if it is long-standing and undiagnosed. Associated history of smoking, gastrooesophagal reflux disease or prolonged intubation may be present. They may also give a history of difficult intubation [6]. Some patients with an acquired laryngeal web may present with stridor [13].

Pulmonary function test may incidentally show an expiratory airway collapse [6]. Peri-operatively, apart from difficult intubation, there may be a desaturation on induction or chest in-drawing due to upper airway obstruction or ventilation with a laryngeal mask airway may require high airway pressures [9]. The end-tidal carbon dioxide tracing may show an obstructive pattern [9]. The laryngeal mask airway would be optimal to ventilate in case a long acting muscle relaxant has already been administered $[5,12]$. The anatomy of the web may be such that it may permit a smaller size endotracheal tube. Alternatively an airway exchange catheter may be used as it has a smaller diameter along with jet ventilation [13].

The fibreoptic bronchoscopy aids in diagnosis [14]. Peroperatively, laser photocoagulation through a rigid bronchoscope may be done if the facility is available $[6,12]$. Following this endotracheal intubation may be done. Subglottic webs may have bizarre clinical presentations. Unanticipated difficult airway still forms about $93 \%$ of the total number of difficult airway scenarios encountered. Following a difficult airway algorithm to tide over the emergency is of utmost importance. After the patient is stabilized, a systematic evaluation helps in appropriate diagnosis and treatment. Extubation should also be staged in these patients as glottic edema may lead to airway obstruction [11].

\section{References}

1. Orhan ME, Gozubuyuk A, Sizlan A, Dere U. Unexpected difficult intubation due to lingual tonsillar hyperplasia in a thoracotomy patient: intubation with the double-lumen tube using stylet and fiberoptic bronchoscopy. J Clin Anesth 2009; 21: 439-441.

2. Sonny A, Nagaraj G, Ramachandran R. Asymptomatic epiglottic cyst: A rare cause of unanticipated difficult intubation. Middle East J Anesthesiol 2011.

3. Nishimori $M$, Matsumoto $M$, Nakagawa $H$, Ichiishi $N$. Unanticipated difficult airway due to undiagnosed 
oropharyngeal stenosis: a case report. JA Clin Reports 2016.

4. Wu G, Li YD, Han XW, Zhang W, Han XP, Ding PX. Sheath-assisted tracheal intubation: A further treatment option for patients with acute dyspnea or asphyxia caused by severe stenosis of the larynx or trachea. Ann Thorac Surg 2011.

5. Meena S, Kumar Ratre B, Bafna U, Deganwa M. Case report unanticipated difficult intubation caused by unexpected laryngeal web in a case of bilateral abductor palsy. Case Rep 2016.

6. Stafford CM, Harrell Ii JH, Winn WR. Subglottic web treated with Nd: YAG Laser. J Bronchol Interv Pulmonol 2018.

7. Redman AG. Osteoma of the thyroid cartilage-an unusual cause of difficult intubation. Br J Radiol 2000; 73: 899-900.

8. Bray RJ. Pharyngeal pouch as a cause of difficult intubation. Anaesthesia 1977; 32: 333-335.

9. Preet MS, Khanna P. Incidental laryngeal web simulating intra-operative refractory bronchospasm Hard palate tumour-a nightmare for the anaesthesiologists-role of modified molar approach. Indian J Anaesth 2013; 57: 6-7.

10. Rutter MJ. Congenital laryngeal anomalies. Braz J Otorhinolaryngol 2014; 80: 533-539.
11. Nabi N, Chaudhary S, Ahuja S, Goel A. A rare case of laryngeal web excision by $\mathrm{CO} 2$ laser in a child: an anaesthetic challenge. J Anaesthesiol Clin Pharmacol 2011; 27: 119-120.

12. Nguyen NK. Unexpected tracheal web encountered during difficult intubation in the operating room. Proc (Bayl Univ Med Cent) 2006; 19: 224-225.

13. Gabriela C, Maria JG, Mariana C, Pedro V, Fernando MM. Unanticipated difficult airway due to a fibrotic subglottic. Anaesthesiol News 2013; 188: 90.

14. Rosenstock CV, Wetterslev J, Astrup G, Afshari A. Diagnostic accuracy of anaesthesiologists' prediction of difficult airway management in daily clinical practice: a cohort study of 188,064 patients registered in the Danish Anaesthesia Database. J Assoc Anaesth Great Br Ireland 2015; 272-281.

\section{*Correspondence to}

Sindhu Sabapathy

Department of Anesthesiology

MVJ Medical College and Research Hospital

India 